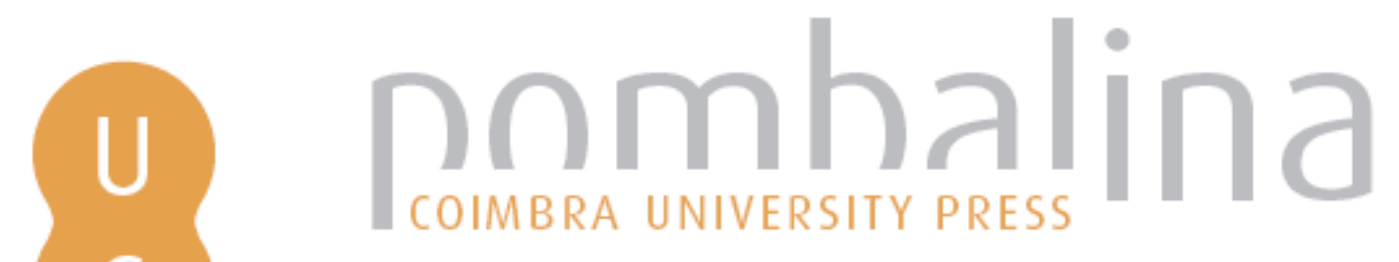

\title{
A alimentação da população adulta da Região Autónoma da Madeira
}

\author{
Autor(es): $\quad$ Sousa, Bruno
}

Publicado por: Imprensa da Universidade de Coimbra; Annablume

URL

persistente: URI:http://hdl.handle.net/10316.2/39651

DOI: $\quad$ DOI:https://doi.org/10.14195/978-989-26-1191-4_22

Accessed : $\quad$ 26-Apr-2023 13:55:23

A navegação consulta e descarregamento dos títulos inseridos nas Bibliotecas Digitais UC Digitalis, UC Pombalina e UC Impactum, pressupõem a aceitação plena e sem reservas dos Termos e Condições de Uso destas Bibliotecas Digitais, disponíveis em https://digitalis.uc.pt/pt-pt/termos.

Conforme exposto nos referidos Termos e Condições de Uso, o descarregamento de títulos de acesso restrito requer uma licença válida de autorização devendo o utilizador aceder ao(s) documento(s) a partir de um endereço de IP da instituição detentora da supramencionada licença.

Ao utilizador é apenas permitido o descarregamento para uso pessoal, pelo que o emprego do(s) título(s) descarregado(s) para outro fim, designadamente comercial, carece de autorização do respetivo autor ou editor da obra.

Na medida em que todas as obras da UC Digitalis se encontram protegidas pelo Código do Direito de Autor e Direitos Conexos e demais legislação aplicável, toda a cópia, parcial ou total, deste documento, nos casos em que é legalmente admitida, deverá conter ou fazer-se acompanhar por este aviso.

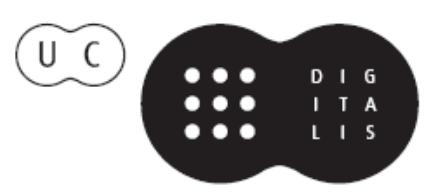




\title{
A alimentação da População adulta da Região Autónoma da Madeira Food habits of the adult population of The Autonomous Region of Madeira
}

\author{
Bruno Sousa \\ Universidade do Porto \\ Faculdade de Ciências da Nutrição e Alimentação
}

Resumo: A alimentação é um determinante da saúde e por isso conhecer os hábitos alimentares de uma população permite diagnosticar os seus erros e possibilita o desenvolvimento de estratégias interventivas de forma a promover comportamentos alimentares saudáveis, preservando a identidade alimentar de um povo.

Assim, o objetivo deste trabalho é reunir os dados existentes sobre a situação alimentar da população adulta da Região Autónoma da Madeira.

Nesta população verificou-se um consumo adequado de cereais e derivados (pão, massa, arroz, milho), tubérculos e raízes (batata, batata-doce, inhame) e de carne, peixe e ovos, e um consumo insuficiente de produtos hortofrutícolas (legumes, hortaliças e fruta), de leite e equivalentes (queijo e iogurte) e de leguminosas (feijão, ervilhas, favas, grão-de-bico). Por outro lado, foi encontrado um consumo elevado de açúcar e produtos açucarados (refrigerantes, sobremesas, bolos), de gorduras e alimentos gordos, e de sal e alimentos salgados. Para além disso, foi detetada uma escolha alimentar pouco variada.

Contudo, estes dados já são de 1998, e por isso está a ser desenvolvido um novo estudo sobre os hábitos alimentares desta população, de forma a caracterizar a sua alimentação no presente, permitindo ainda avaliar as tendências de consumo alimentar. Palavras-chave: Alimentação, Nutrição, Hábitos alimentares, Adultos, Região Autónoma da Madeira.

Авsтract: Food is a key determinant of health and as such knowing the food habits of a population allows to diagnose their errors and grants the development of interventional strategies so as to promote healthy eating behaviour, preserving a people's food identity.

Thus, the objective of this work is to gather existing data on the food status of the adult population of the Autonomous Region of Madeira.

In this population one found an adequate intake of cereals and cereal derivatives (bread, pasta, rice, maize), tubers and roots (potato, sweet potato, yam), meat, fish and eggs, but insufficient consumption of fruit and vegetable products, milk and equivalents (cheese and yogurt) and vegetables (beans, peas, broad beans, chickpeas). On the other hand, one found high intake of sugar and sugar products (soft drinks, desserts, and cakes), fats and fatty food, and salt and savoury food. In addition, food choice was found to be little varied. 
However, these data is from 1998, so a new study of food habits of this population is under development in order to characterize current food habits, still allowing an assessment of food consumption trends.

KeYwords: Food, Nutrition, Eating habits, Adults, Autonomous Region of Madeira.

Atualmente verifica-se no nosso país uma elevada prevalência de doenças crónicas, resultado de hábitos mantidos ao longo de vários anos, de entre os quais a alimentação assume papel de relevo.

As doenças cardiovasculares e cerebrovasculares constituem as principais causas de mortalidade e morbilidade nos países desenvolvidos, e Portugal não se afasta deste panorama, apresentando uma das mais altas taxas de mortalidade cerebrovasculares da Europa. A par destas doenças, muitas outras, também responsáveis por elevados nível de mortalidade e morbilidade estão relacionadas com os hábitos alimentares. Para além disso, sabe-se que uma grande parte destas doenças são evitáveis, e por isso é imperioso reforçar a importância da prevenção e da promoção de uma alimentação saudável, salvaguardando as tradições e costumes dos povos, preservando toda a sua identidade alimentar.

Por outro lado, o conhecimento dos hábitos e comportamentos alimentares de uma população, possibilita definir políticas e escolher intervenções adequadas para combater e prevenir os problemas de saúde relacionados com a alimentação e aumentar deste modo o bem-estar individual e coletivo, assim como o nível sanitário da população.

Este trabalho pretende assim reunir os dados existentes sobre a situação alimentar da população adulta da Região Autónoma da Madeira.

Em 1998, a Secretaria Regional dos Assuntos Sociais realizou o primeiro diagnóstico da situação alimentar e nutricional da Região Autónoma da Madeira, dada a pertinência em conhecer os hábitos alimentares desta população que não estavam determinados, tendo sido publicados os seus resultados um ano mais tarde. Tratou-se de um estudo transversal, que teve como objetivo geral conhecer a situação alimentar da população adulta (18 - 74 anos), tendo posteriormente a intenção de elaborar recomendações alimentares e delinear estratégias de intervenção adequadas.

Neste estudo, ao nível da estruturação do dia alimentar, verificou-se que a refeição mais omitida é o pequeno-almoço, seguindo-se do jantar, e que é mais frequente na faixa etária mais jovem e ao domingo. A refeição menos omitida é o almoço, e as merendas eram mais frequentes nos mais jovens, nos que trabalham, e nos que tinham um nível de educação e de rendimento mais elevados. Os indivíduos com idade superior parecem assim dar mais relevância às principais refeições e menos às merendas do que a população 
mais jovem, denotando-se que a prática regular das merendas ainda se está a enraizar nesta população.

Nesta população, o local de preferência para fazer as principais refeições é o ambiente familiar, aumentando a sua frequência à medida que aumenta a idade dos indivíduos. A refeição realizada com maior frequência fora de casa é o almoço.

Quase metade desta população tomava o pequeno-almoço sem companhia, e o jantar é a refeição em foi encontrada uma menor frequência de indivíduos a comerem sozinhos, sendo de realçar que comer sem companhia é mais frequente nos indivíduos com idades superiores. Destes factos, a situação mais preocupante está relacionada com o pequeno-almoço, pois, desta forma, as crianças não observam os adultos com quem vivem, que são autênticas referências, a fazerem esta refeição, podendo levar os mais novos a adoptarem os hábitos alimentares que não são os mais adequados.

Relativamente ao tempo que esta população dedica às refeições não é muito elevado, contrariando o indicado de fazer as refeições com calma, proporcionando também uma adequada mastigação dos alimentos.

Neste trabalho, foi também determinado o consumo alimentar da população da Região Autónoma da Madeira e verificou-se que existia um baixo consumo de leite e equivalentes particularmente na faixa etária mais elevada, com metade do consumo que era recomendável; um consumo de carne superior ao do peixe; um consumo de manteiga que decresce com o aumento da idade dos indivíduos; um consumo de pão em $90 \%$ da população, com uma média de 90 gramas diárias, encontrando também um consumo de massa, arroz e milho, segundo esta ordem de frequência de consumo; uma ingestão de tubérculos e raízes (batata, batata doce e inhame) em $75 \%$ da população; um consumo de legumes e hortaliças em $50 \%$ do recomendável; uma ingestão média de fruta diária de duas peças pequenas; uma adição média diária de dois pacotes de açúcar aos alimentos, que contabilizando o que está integrado em alimentos ou bebidas como refrigerantes, bolos, sobremesas, entre outros, este consumo ultrapassa em muito o que é recomendável; um consumo de bebidas alcoólicas em 30\% da população, sendo que os mais jovens preferem a cerveja e os mais velhos o vinho; e um consumo de refrigerantes de meio litro por dia, encontrado no grupo etário mais jovem.

Desta forma, podemos dizer que a alimentação dos madeirenses caracterizava-se por:

- Um consumo adequado de:

- Cereais e derivados (pão, massa, arroz, milho);

- Tubérculos e raízes (batata, batata doce, inhame);

- Carne, peixe e ovos.

- Um consumo insuficiente de:

- Produtos hortofrutícolas (legumes, hortaliças, frutas); 
- Leite e equivalentes (queijo, iogurte);

- Leguminosas (feijão, ervilhas, favas, grão-de-bico).

- Um consumo elevado de:

- Açúcar e produtos açucarados (refrigerantes, sobremesas, bolos);

- Gorduras e alimentos gordos;

- Sal e alimentos salgados;

- Bebidas alcoólicas.

- Uma escolha alimentar pouco variada.

Esta caracterização alimentar, retrata muito daquilo que também acontece a nível nacional e no mundo ocidental, resultado da globalização e do estímulo ao consumismo, que resulta numa ingestão alimentar reduzida em muitos produtos alimentares frescos, ricos nutricionalmente, e num consumo elevado de produtos industrializados, desadequados do ponto de vista nutricional, que fogem à alimentação tradicional tão rica desta população e que ao mesmo tempo comprometem o seu estado de saúde.

Além da caracterização do padrão alimentar desta população, foi ainda possível obter outros dados relativos à informação e conhecimentos relativos à alimentação. Neste âmbito, verificamos que esta população estava muito satisfeita com as suas práticas alimentares e considerou mesmo estar bem informada sobre a alimentação, contudo, curiosamente, a maior parte destes indivíduos ainda desejavam receber mais informações sobre esta temática. A principal fonte de informação mencionada foi os amigos e familiares, sendo seguida pelos meios de comunicação e então posteriormente pelos profissionais de saúde.

Quando foram avaliados os conhecimentos desta população sobre a alimentação verificou-se que eram baixos e que persistem ideias falsas associadas a determinadas práticas alimentares.

$\mathrm{Na}$ compra dos alimentos, esta população manifestou que nem sempre lê as informações nutricionais dos rótulos, estando esta situação associada à idade, aos rendimentos, ao nível de instrução, à profissão e ao local da habitação.

Relativamente aos fatores que mais influenciam a escolha alimentar foram em primeiro lugar os hábitos alimentares da família, sendo seguidos pela saúde, o custo, o tempo de preparação e por fim a publicidade.

Após este primeiro diagnóstico, as estratégias implementadas estiveram relacionadas com atividades pontuais, promotoras de uma alimentação saudável, privilegiando a informação da população, sem serem estruturadas num programa regional de intervenção em função dos resultados encontrados, nem direcionadas especificamente para os principais erros alimentares detectados.

Todos estes dados referem-se a 1998 , que podem não refletir a realidade atual, contudo são os únicos dados disponíveis sobre a alimentação da população adulta da Região Autónoma da Madeira. 
Assim, foi sentida a necessidade de realizar um novo estudo sobre os hábitos alimentares desta população, e que está atualmente a ser desenvolvido pelo Serviço de Saúde da Região Autónoma da Madeira, de forma a caracterizar a sua alimentação, nomeadamente ao nível da organização do dia alimentar, a composição alimentar e nutricional do dia alimentar e os erros alimentares, constituindo ainda uma oportunidade para avaliar as tendências de consumo alimentar, quando comparado com o estudo anterior.

Por outro lado, apesar de se perspetivar um agravamento da situação alimentar, existe ainda pouca informação disponível sobre as escolhas alimentares num contexto de crise, como a que o nosso país tem passado, colocando-se várias questões que gostaríamos de saber: Será que desapareceram as tendências de consumo alimentar anteriores? Será que a crise acabou de vez com a sociedade de hiperconsumo? Constituirá a crise uma oportunidade para repensar o nosso modelo de consumo alimentar?

Enfim, questões que reforçam a importância de realizar este novo diagnóstico alimentar, contudo salienta-se que o mais importante será mesmo conhecer os hábitos alimentares desta população no presente, detetar erros, planear estratégias e efetivá-las, para que esta população tenha uma alimentação promotora de saúde e que ao mesmo tempo se consiga preservar o património alimentar desta região, específico, e que pode perfeitamente enquadrar-se num padrão alimentar saudável, e assim evitar as inúmeras doenças que afetam esta população que, realce-se, podem ser evitáveis pela alimentação.

Em conclusão, podemos dizer que face ao que é conhecido, a população da Região Autónoma da Madeira apresenta alguns erros alimentares, nomeadamente um consumo insuficiente de produtos hortofrutícolas, leite e equivalentes, e leguminosas e pelo contrário uma elevada ingestão de açúcar e produtos açucarados, gorduras e alimentos gordos, sal e alimentos salgados, e de bebidas alcoólicas, apresentando ainda uma alimentação pouco variada. Esta população considera que tem uma alimentação saudável e está bem informada sobre a alimentação, mas na realidade verifica-se que tem um baixo nível de conhecimentos sobre a alimentação e que persistem ideias falsas associadas a determinadas práticas alimentares. Contudo, a maioria desta população está recetiva a aumentar os seus conhecimentos sobre a alimentação.

Ficou ainda realçada a importância da nova avaliação que está em curso e que vai permitir de uma forma clara identificar o padrão alimentar atual, analisar as tendências alimentares, e provavelmente reforçar ainda mais o que já foi demonstrado no primeiro diagnóstico, que algumas tradições alimentares características deste povo, intrínsecas e culturais, e ao mesmo tempo saudáveis, estão a perder-se, com repercussões ao nível da saúde, demonstrando a necessidade de efetivar estratégias num programa regional para corrigir os erros alimentares encontrados. 
Bruno Sousa

\section{Bibliografia}

- Direção Geral da Saúde (2012), Plano Nacional de Saúde 2012 - 2016. Lisboa.

- Oshaug, A. (1994, $2^{\text {nd }}$ ed.), Planning $\&$ Managing Community Nutrition Work, University of Oslo, Oslo.

- Secretaria Regional dos Assuntos Sociais e Parlamentares (1999), Diagnóstico da situação alimentar e nutricional da Região Autónoma da Madeira, Funchal.

- Secretaria Regional dos Assuntos Sociais (2003), Plano de Saúde, Funchal.

- World Health Organization (2008), The World Health Report 2008:Primary Health Care Now Than Ever, Geneva. 